\title{
The Bönhamn Declaration
}

A statement by the participants of the 9th Royal Colloquium hosted by His Majesty King Carl XVI Gustaf of Sweden. The Colloquium was held from 14 to 17 June 2009 in Bönhamn on a World Heritage Site, the High Coast of Sweden. His Majesty was joined by 19 international scholars to explore issues relating to "Climate Action: Tuning in on Energy, Water and Food Security".

Climate action is a highly topical issue on the international political agenda. Due to the complexity of the climate system and its interactions with all facets of nature and society, the step from analysis to action becomes critical. To provide water, food and energy to a growing world population in an equitable manner is a monumental challenge. To find a way forward, which at the same time offsets the negative consequences of climate change and at best minimizes the anthropogenic influences on the climate, will need novel solutions, technical innovations and new ways of thinking about development. Faced with uncertainties and conflicting interests in a world plagued by economic crises, timely political actions pose major difficulties.

To reach a sustainable balance between supply and demand of natural resources, efficiency of use is seen to be a key to progress. To meet the challenges of energy, food and water security, we need:

- to apply transdisciplinary scientific approaches,

- to find ways of speeding up technical innovation through increased R\&D in relevant areas and

- to rethink policy and to focus on actions that address not just climate change, but a wide spectre of fundamental human needs for development.

Bönhamn

17 June 2009 